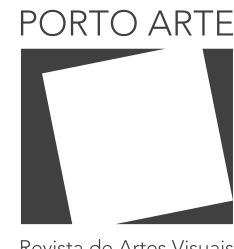

v. 25 ก. 43 Jan/jun 2020 e-ISSN: 2179-8001

\title{
Arquiteturas expositivas: debates conceituais em tempos de crise
}

Architectures of Exhibitions: conceptual debates in time of crisis

\section{Mirtes Marins de Oliveira}

ORCID: 0000-0002-7132-0875

Universidade Anhembi Morumbi, Brasil

\section{Luisa Angélica Paraguai}

ORCID: 0000-0002-3886-8118

Pontificia Universidade Católica de Campinas, Brasil

\section{Resumo}

A pandemia de COVID-19 impactou o que parecia ser valor diferencial das exposições: o contato com a materialidade de obras e documentos acessados pelo deslocamento do corpo dos visitantes no espaço físico, captando sonoridades, luminosidades, cheiros, fluxos e ritmos de percursos. O horizonte de isolamento social tirou de cena momentaneamente a exposição tradicional e estimulou a oferta de visitações aos espaços digitais como outra possibilidade de experiência no espaço físico ou da narrativa expositiva. O artigo pretende discutir semelhanças e distâncias entre essas diferentes arquiteturas para pensar os limites e o próprio conceito de exposição e curadoria em novo contexto.

Palavras-chave

Design de exposições. Arquitetura. Arquitetura da informação.

\section{Abstract}

COVID-19 epidemic impacted what seems to be the differential value of the exhibitions: the contact with the materiality of works and documents accessed by displacement of the visitors' bodies in the physical space, capturing sounds, luminosities, smells, flows and rhythms routes. The horizon of social isolation temporarily removed the traditional exhibition and stimulated institutions to offer visitors digital spaces as another possibility of experience in the physical space or of the exhibition narrative. The article intends to discuss similarities and distances between these different architectures to think the limits and the concept of exhibition and curatorship in a new context.

Keywords

Exhibitions design. Architecture. Information architecture. 


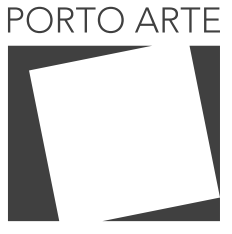

Revista de Artes Visuais

$\times 25 n .43$

Jan/jun 2020 e-ISSN: 2179-8001

Estudar exposições necessariamente exige uma desnaturalização do termo, buscando captar suas origens históricas e, portanto, funções localizadas, circunstanciais. O formato exposição se configura ao longo do tempo (ao menos no ocidente) como processos em adequação tanto ao que o capitalismo exige como elemento importante nas estratégias de sedução mercadológica - tais como as feiras ou espaços comerciais - ou de propagação de visões de mundo quanto, em contrapartida, como espaço público provocador e antagônico em relação às mesmas estratégias. Ao longo do tempo, certos formatos foram de tal maneira divulgados e apresentados como objetivos e neutros que passaram a ser apresentados como universais, dentro do enquadramentos modernistas que propagaram a necessidade dessa premissa, como exemplo a noção, a partir do Museu de Arte Moderna de Nova York, do cubo branco. Porém, também a vertente experimentalista dos mesmos modernismos, propôs a desconstrução do modelo e buscou provocar a participação ou forte interferência do visitante. Como exemplo, citam-se as experiências realizadas pelos artistas e arquitetos das vanguardas históricas européias buscando desconstruir o modelo consagrado expositivo e, em período posterior, os movimentos de contracultura ao final dos anos 1960 no Brasil e internacionais, que colocavam em xeque a noção de arte por meio de práticas experimentais artísticas e também em relação às formas de mostrar.

Bennett (1995) é referência incontornável no debate sobre a constituição histórica dos museus e de exposições - a partir dos séculos XVIII e XIX - que, em abordagem foucaultiana, alinha politicamente o museu moderno ao racionalismo que também organiza outras instituições como as bibliotecas, por exemplo. Para o autor, museus, exposições internacionais e feiras estão envolvidas em um projeto do que denomina mostrar e narrar: exibição calculada na constituição de um espaço que reforça valores e significados culturais hegemônicos. Um aspecto fundamental que surge desde esses primórdios é a preocupação de condução do visitante na narrativa a partir de elementos de visualidade. Para Pallasma (2011, p. 26) este sentido dominante "define de maneira inquestionável a arquitetura dos olhos", apontando para uma condição ocidental que se define nas superfícies aparentes das imagens na instantaneidade da contemporaneidade. Corroborando historicamente a afirmação de Pallasma (2011) e também os estudos de Bennett (1995), há a indicação de Crary (2012), para quem há o deslocamento sinalizado pela passagem da óptica geométrica dos séculos XVII e XVIII à óptica fisiológica que dominou os debates científicos e filosóficos sobre a visão no século XIX. Para Crary (2012, p. 25) tal situação levou ao acúmulo do conhecimento sobre o papel do corpo na apreensão do mundo visível, que leva à conclusão de que "a eficiência e a racionalização em muitas áreas da atividade humana dependiam da informação sobre as capacidades do olho humano". Essa nova configuração também aponta, em Crary (Ibidem), "para um ordenamento do conhecimento sobre o corpo e da relação constitutiva desse saber com o poder social", indicando que a questão das formas expositivas é, mais do que um arranjo prático sobre qualidades positivas de transmissão de informação, um elemento poderoso na oferta, introjeção e convencimento de teses artísticas, culturais e comerciais. Essa qualidade, pode ser justaposta aos estudos de Bennett (1995), para quem as instituições racionalistas - museus, ex- 


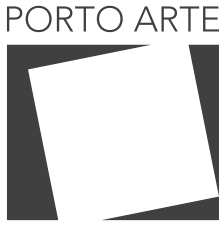

Revista de Artes Visuais v. 25 ก. 43 Jan/jun 2020 e-ISSN. $2179-8001$

posições internacionais e feiras - compartilham a preocupação em regular os aspectos perfomativos da condução dos visitantes - seus olhos, seus corpos. Para esses são oferecidas diferentes formas de caminhar organizado, no qual a mensagem projetada é comunicada sob a forma de itinerário dirigido. Para o autor, com a inauguração do museu público também ocorre o nascimento de novas relações governamentais com a cultura, tratada como novo instrumento de gestão social.

\begin{abstract}
Isso envolve considerar sobre a maneira pelas quais o museu, ao providenciar um novo cenário para trabalhos de cultura, também funcionou como um ambiente tecnológico que permitiu que artefatos culturais fossem remodelados de formas que facilitariam desdobramentos para novos propósitos, partes de programas governamentais com objetivo de reformular normas gerais de comportamento social (BENNETT, 1995, P. 6).
\end{abstract}

Regular a conduta dos visitantes era, segundo o autor, missão a ser solucionada por propostas arquitetônicas e tecnológicas, rapidamente disseminadas pelo circuito institucional e alinhadas aos valores da civilização industrial. Assim, nesse direcionamento, o sentido dominante da visão tem sido definidor para a prática no/do espaço, pois o observador vincula desde então sua experiência e compreensão de mundo por meio das extensões tecnológicas da visão e da proliferação de imagens na contemporaneidade. Como afirma Wartofsky (apud PALLASMAA, 2011, p. 26) "a visão humana em si é um artefato, produzido por outros artefatos, que são as fotografias".

Por fim, nesse desenho de possibilidades originárias dos espaços expositivos, cabe apontar que Bennett (1995) demonstra a ambiguidade da posição do homem nessa ordem formal, como sujeito e, ao mesmo tempo, objeto do saber que organiza e, colocado, na apreciação da narrativa expositiva, como o final e ápice de um desenvolvimento evolucionário. Conclui-se, em suas afirmações, que as exposições (de todas dimensões, categorias e segmentos) promovem a celebração de quem as organiza. Também para o autor, o que dá suporte às politicas do museu contemporâneo tem raizes na tensão entre a suposta universalidade do objeto de conhecimento - homem - e as maneiras pelas quais a parcialidade social é realizada e encarnada nos displays dos museus. Estes configuram-se também como lugares de exibição de poder e, segundo nossa perspectiva, da mesma maneira ocorre com aqueles locais das exposições não institucionais. Assim, compreende-se, e não apenas por este autor, que a arquitetura é o eixo central em torno do qual a noção de exposição será desenvolvida neste texto, determinando portanto a necessidade de seu escrutínio crítico como estratégia de compreensão dos projetos de mostras institucionais, comerciais ou outras.

A arquitetura física das exposições é um programa que institui um sistema de valores (assim como outras instituições que se configuram em edifícios, tais como escolas, hospitais etc) que organiza a aprendizagem sensorial e motora, com direcionamentos estéticos, culturais e ideológicos (VIÑAO FRAGO e ESCOLANO, 2001). Assim como 




Revista de Artes Visuais

$\vee 25 n .43$

Jan/jun 2020 e-ISSN: 2179-8001

no campo educacional, as arquiteturas das exposições oferecem um "currículo oculto".

De forma naturalizada conduzem o visitante em um roteiro de compreensão do mundo, pautado em documentos e obras que o corroboram de maneira afirmativa: as exposições não mentem porque está tudo comprovado nos objetos e suas materialidades. No entanto, na vida contemporânea a noção da arquitetura expositiva pode ser ampliada e/ou deslocada pelo uso das interfaces digitais e suas respectivas materialidades, colaborando na expansão da experiência do visitante e, por vezes, promovendo abertura para justaposição de elementos que podem colaborar tanto para um envolvimento crítico com o que se vivencia no espaço expositivo quanto para uma relação deslumbrada quanto aos elementos tecnológicos.

o computador também conta como uma tecnologia de inscrição, porque altera as polaridades elétricas e correlaciona estas mudanças com o código binário, linguagens de alto nível como $\mathrm{C}++$ e java e os brilhos de fósforo do tubo de raios catódicos (HAYLES, 2002, p. 24, nossa tradução ${ }^{1}$ ).

A partir de Hayles (2002) assumimos que as propriedades das interfaces digitais, ora cada vez mais imbricadas com os artefatos físicos, têm provocado impactos na organização de nossas interações e portanto definido outras convenções que mobilizam os espaços informacionais no mundo: circulação e projeção. As experiências que articulam essas dimensões - passaram a ser revistas e aprimoradas no momento atual, enquanto não há certeza sobre o tamanho e estágio da pandemia de COVID-19 no Brasil. Sendo que as notícias sobre as primeiras aberturas de museus na Europa para visitantes definem um formato que considera a possibilidade de continuidade de ondas da doença e seguindo, portanto, normativas de segurança para evitar contágio. Segundo matérias jornalísticas (ROGERS, 2020), essas normativas incluem uso de máscaras, eliminação de uso de guias em áudio, barreiras transparentes para proteção dos funcionários, além de manutenção de distanciamento social, integração de estações para desinfecção das mãos, e dificuldades em ações de interatividade. Especial atenção aos novos protocolos de circulação: distanciamento entre os visitantes e entre os funcionários - conforme Rogers (2020) aponta, além do distanciamento das obras, agora também é necessário que se distancie dos outros visitantes. A disciplina dos corpos - pauta das propostas de espaços expositivos desde sua organização a partir do século XVIII - passa a ser obrigatória e quase naturalizada por motivos de saúde. $\mathrm{Na}$ implementação daqueles espaços, a arquitetura passou a ocupar a centralidade das preocupações de seus elaboradores. Em consonância com o entendimento da arquitetura e urbanismo como o fator de organização da sociedade, as exposições passaram a cumprir ao longo do século XIX um papel de domesticador dos públicos em situação de observação de uma visualidade narrativa. Mas se Bennett aponta para essa situação 




Revista de Artes Visuais

$\vee 25 n .43$

Jan/jun 2020 e-ISSN: 2179-8001

de forma crítica, a domesticação dos corpos em contextos atuais, em uma perspectiva pós pandemia, surge como prática necessária.

Esse novo contexto instigou as autoras a buscarem elaborar uma compreensão dos modelos expositivos pré pandemia, observar algumas experiências na condição do isolamento social e avaliar possibilidades (como a citada) de retorno do que se considera normal, a partir de novas restrições da relação do corpo na arquitetura das mostras.

Nesse sentido, da perspectiva do presente artigo, parte-se da premissa de que é necessário acoplar ao sentido tradicional (e suas funções no contexto do capitalismo) de arquitetura aqueles elementos que constituem as concepções contemporâneas elaboradas em conjunto com o contexto digital para colaborar na reflexão de novos ambientes expositivos no pós pandemia.

Vive-se, contemporaneamente, em sociedade que continuamente experimenta construções sociais, de trabalho e pessoais em rede conformadas pelos dispositivos tecnológicos que tornam o indivíduo acessível/conectado ao outro, ainda que distante fisicamente. A tecnologia digital, assim, sugere indiciar o corpo e os movimentos de interação, individual e coletivamente, entre dimensões de ação possíveis pois, diferentemente de outras mídias, instala as informações e possíveis trocas conformadas pelas conexões que mobilizam os usuários em diversos percursos possíveis entre conteúdos e narrativas. Assim, o contexto de atualização dos dados configura-se enquanto ativação de uma rede de significados em uma certa condição de acesso. Em constante construção e renegociação de sentido, as conexões efetivadas, ainda que previamente programadas e definidas pela estrutura hipertextual, terminam por redesenhar a todo momento o próprio espaço comunicacional. Importa-nos compreender o tempo de atuação dos participantes diante da ocorrência dos eventos entre fluxos contínuos e/ou pontuais, pois tem definido os processos, procedimentos e ações na configuração formal da comunicação (PARAGUAI, 1999).

Assim, considerando estes fluxos informacionais, pretende-se, neste texto contextualizar a circulação dos usuários em espaços expositivos digitais, pois contemporaneamente, diante da condição de isolamento social devido à pandemia, vem sendo colocados como possíveis interlocutores para efetivação da experiência museal, até então considerada fundamentalmente uma experiência física e eventualmente acoplando elementos digitais. Experiências anteriores ao contexto atual já indicavam o desafio, apresentado então como uma possibilidade de expansão da experiência de visitação às exposições ou como uma prática que ampliaria o acesso de públicos distantes fisicamente. Como exemplo, a exposição online "Migrações à Mesa" (http://artsandculture.google.com/exhibit/), que passou a integrar a plataforma Google Arts \& Culture (http://artsandculture.google.com) em 30 de maio de 2020, mas foi anteriormente exibida no Museu da Imigração do Estado de São Paulo entre novembro de 2016 e setembro de 2017. 




Revista de Artes Visuais

v.25 n.43 Jan/jun 2020 e-ISSN: 2179-8001
Figura 1: [a] e [b] Objetos de cozinha e documentos compartilhados pelas famílias. Fonte: <http:// museudaimigracao.org.br/ exposicoes/temporarias/ migracoes-a-mesa>. [c] Vista da exposição no Museu

da Imigração do Estado de

São Paulo. Fonte: <http:// www.stdm.com.br/migraesmesa>. Fotografia: PC Pereira Acesso em: jun. 2020
A exposição "Migrações à mesa"2, montada primeiramente no Museu da Imigração do Estado de São Paulo em 2016 (figura 1), com o objetivo de relatar as relações afetivas dos imigrantes com seus hábitos alimentares, promoveu uma ação participativa pelas redes sociais com a participação de dez famílias, que incluíram na época objetos pessoais, como os cadernos de receita e objetos de cozinha (figura 1a e 1b), apresentando, portanto, uma curadoria participativa, coletiva. Os cadernos de receitas são, além de repositórios das heranças culturais, objetos concretos e singulares que em seu aspecto material - como o papel, a tinta, e conforme seu manuseio - a caligrafia, o idioma, tornam-se índices das relações sociais e familiares (STDM, 2016).

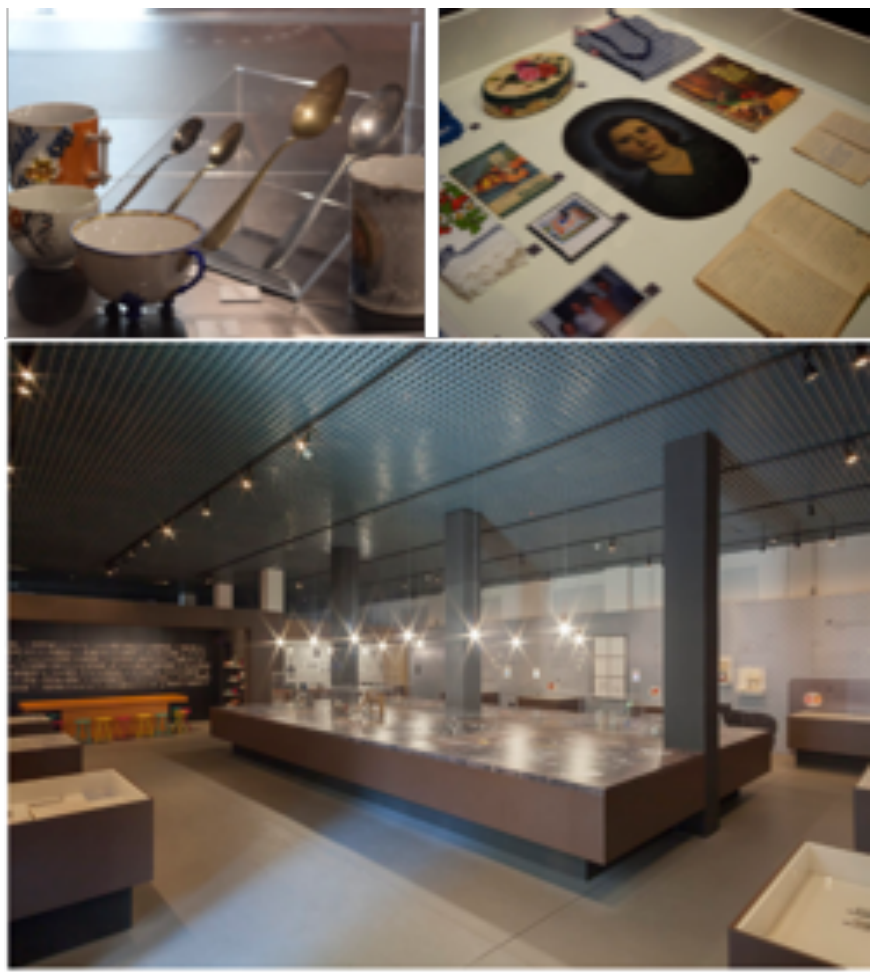

Neste exercício de construção conjunta, quando a exposição foi adaptada pelo Museu da UFRGS para a região do Rio Grande do Sul, entre 18 de dezembro de 2018 e 31 de agosto de 2019, buscou-se dar visibilidade e oferecer lugar de fala para culturas não midiatizadas e mesmo em risco de desaparecimento com participação efetiva, agregada aos esforços de pesquisa, de comunidades quilombolas, guarani-mbyá, kaingang, entre outras. A plataforma educacional na qual se estendia implicava também a participação dos públicos.

\footnotetext{
2- Exposição "Migrações à mesa" com curadoria de Angélica Beghini, Mariana Esteves Martins e Marília Bonas. Expografia e produção executiva de Juliana Silveira e Vivian Bortolotti. Identidade visual e Design ambiental do Studio STD M com fotos de PC Pereira (STDM, 2016).
} 


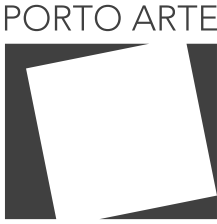

Revista de Artes Visuais

v. 25 ก. 43 Jan/jun 2020 e-ISSN: 2179-8001
Figura 2: "Linhas que conectam os cartões e tapetes podem ser introduzidas em várias posições. O diagrama pode representar os principais caminhos de navegação adicionando um número mínimo de linhas no plano base. As linhas também podem ser adicionadas a outras posições que representam caminhos em um processo específico (a linha sólida à esquerda), o fluxo de informações entre as páginas (o arco pontilhado) ou os links que levam ao site para outras páginas na Internet (a linha

sólida à direita)". Fonte: (KAHN et al., 2001, p. 225, nossa tradução*).
A circulação física permitia o trânsito entre mesas, que buscaram formalizar um espaço visual para evocar os sabores familiares. Vale apontar que o sentido do paladar em conjunto com o do olfato nos fazem "reentrar de modo inconsciente um espaço totalmente esquecido da memória da retina" (PALLASMAA, 2011, p. 51). E é deste encontro físico entre objetos e sensações pelos visitantes que os objetivos da exposição vão sendo constituídos. Desta maneira entende-se que a arquitetura do espaço físico evoca um todo indivisível de impressões, táteis, sonoras, visuais, a partir de uma geometria que para o autor "enquadra, detém, reforça e foca nossos pensamentos, além de evitar que eles se percam" (Ibid., p. 42).

Na proposta digital dessa exposição, há que se listar as diferenças consistentes entre as duas situações, cabendo apontar de antemão para o fato de que a exposição física pode incorporar o digital como elemento constituinte. No entanto, o oposto, na exposição digital, o espaço físico aparece em sua condição de registro, estando portanto, submetido aos enquadramentos precisos de seus documentadores.

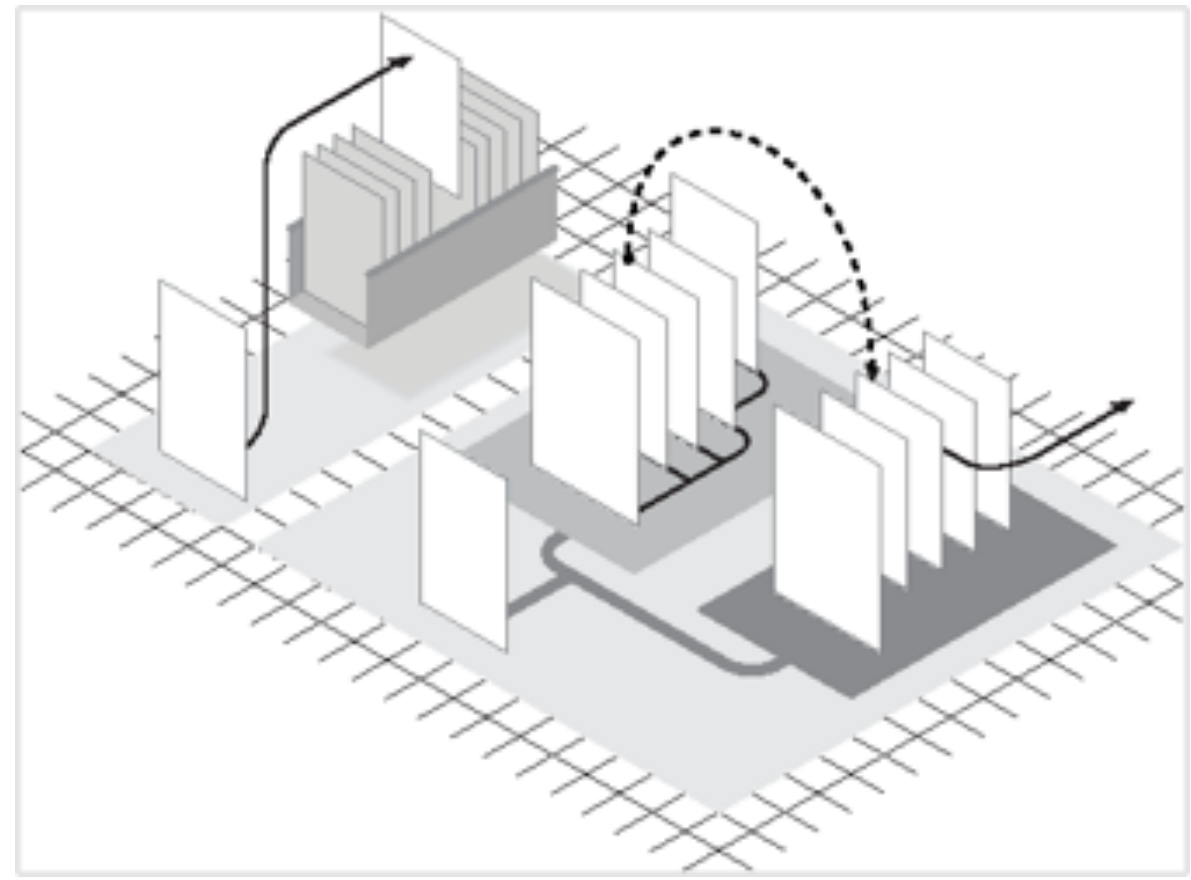

Questão discutida entre autores (BAYER, 1940; BENNETT, 1995; O'DOHERTY, 2002; CRIMP, 2005) que tratam de exposições e curadorias (nem sempre de forma crítica) é o caráter arbitrário das mostras, mas que se apresenta naturalizado para os visitantes. No entanto, no espaço físico há a possibilidade de transgressão dessa arbitrariedade, utilizando para isso as próprias possibilidades digitais em tempo real, além de estabelecimento das justaposições físicas proporcionadas pelo caminhar no espaço. No espaço físico é possível buscar ângulos inusitados e é possível consultar a web e ter informações que a exposição sonega. Na exposição da perspectiva digital, é 




Revista de Artes Visuais

$\vee 25 n .43$

Jan/jun 2020 e-ISSN: 2179-8001

possível fazer buscas na internet e agregar informações críticas. Porém, a linearidade da narrativa é mais evidente e difícil de contornar, afinal além da edição curatorial, há a curadoria das imagens mostradas. No caso de "Migrações à Mesa", a mostra online não é 360 graus, que poderia permitir certa exploração panorâmica do espaço físico. Trata de apresentar o conteúdo fotográfico por uma série de slides mostrados em sequência por ação do visitante do website.

A tradicional leitura das possibilidades expositivas que considera as mostras como lugares de educação, laudatória ou crítica, e a premissa de que o contato ao vivo com obras e documentos são insubstituíveis para os sentidos e compreensão dos significados que tais artefatos são um motivo de reflexão aqui. A exposição em um website pode servir como um complemento, porém, na falta do espaço físico no qual a mostra inicialmente se deu, a função complementar é finalizada e a nova configuração deveria dar conta de toda a relação com os públicos. Das mais afirmativas às mais ambíguas.

Mas, em meio à pandemia há um rompimento da máxima educacional e algumas pessoas (as que têm acesso aos dispositivos digitais e às redes) vem circulando pelos espaços museais e das mostras através do acesso digital. Até quando essa condição indica um novo parâmetro para a elaboração de curadorias e exposições não é claro. Espera-se que esse momento de crise seja passageiro e que retornando aos ambientes físicos de museus e mostras, a reflexão sobre essa composição de formatos desdobre-se em possíveis outros entendimentos e práticas expositivas. Alguns autores que tratam do eixo arquitetônico, suas premissas e consequências em exposições físicas (DEL CASTILLO, 2008; LOCKER, 2011; HUGHES, 2010; CRIMP, 2005; O'DOHERTY, 2002; entre outros), portanto, passamos aqui a demonstrar a noção de arquitetura da informação no ambiente Web e as interações entre as dimensões física e digital a partir da observação da condição expositiva em momentos de isolamento social.

\section{Arquitetura da Informação e seus fluxos}

Quando se fala de fluxos de informação ponderamos primeiramente definir com Macedo (2005, apud OLIVEIRA et al., 2015) a "Arquitetura da Informação" enquanto "características de uma disciplina que se estabeleceu no contexto da ciência pós-moderna", ao questionar mecanismos lineares e o determinismo para estabelecer a multiplicidade e inter-penetração como conceitos operatórios de sistemas mais abertos e, portanto, interativos. Assim, a organização informacional de documentos, publicações, e/ou obras em ambientes digitais define-se pela navegação entre links por parte do usuário, que possibilita nominar zonas de interesse e de desinteresse. Este processo de escolhas pode ser representado pela forma visual do diagrama espacial "slide tray", como indicado na figura $02^{3}$, de Krzysztof Lenk (BRADFORD apud WURMAN, 1997, p. 5). Os autores Kahn et al. (2001) referenciando esta lógica propõem graficamente as

\footnotetext{
3-"Lines connecting cards and carpets can be introduced in several positions. The diagram can represent main navigational paths by adding a minimum number of lines on the base plane. Lines can also be added to other positions representing pathways in a specific process (the solid line on the left), the flow of information between pages (the dotted arc), or links that lead out of the web site to other pages on the Internet (the solid line on the right)" (KAHN et al., 2001, p. 225)
} 


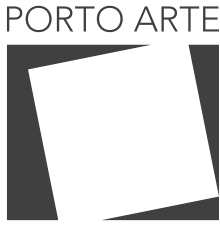

Revista de Artes Visuais

$\vee 25 n .43$

Jan/jun 2020 e-ISSN: 2179-8001

possíveis conexões internas e externas conformadas pelas linhas contínua e tracejada, indicativas dos modos de acesso às informações, ainda que as páginas se apresentem em grupos sequenciais e lineares em cada bloco (figura 02).

Esta técnica de visualização coloca a estrutura informacional como espaço a ser percorrido, e que portanto congrega movimentos horizontal (eixo x) e vertical (eixo y) de acesso, bem como insere a característica temporal no processo de navegação quando apresenta a dimensão de profundidade. Este eixo Z implica a sucessão linear de eventos em cada bloco, na medida em que posiciona um cartão na frente de outro, e também localiza as possíveis conexões através de linhas, tracejadas ou contínuas, com setas. Este esforço sistemático de definir padrões e modos de leitura é compreendido por Albuquerque e Lima-Marques (2011, p. 68) como Arquitetura de Informação, "cujo propósito é a representação e a manipulação de informações, bem como a criação de relacionamentos entre entidades linguísticas para a definição desses espaços de informação". Para os autores, trata-se de uma investigação epistemológica da narrativa, pois busca identificar e relacionar dimensões para o documento a ser produzido, como forma, contexto, manifestação e significado.

Ao buscar compreender os processos de sistematização da informação em ambientes digitais reconhecemos a complexidade desta disciplina, ainda que possa aplicar princípios mais ou menos simples, e que também resultam em estruturas de busca. Observa-se uma organização semântica (lógica e associativa) da informação, que envolve a codificação de um conjunto de dados com um conjunto de esquemas organizacionais conceituais sobrepostos ou multifacetados, como as funções de navegar, pesquisar, aprender um conceito ou executar uma tarefa com base nas informações. Essa estrutura hierárquica também pode acessar informações por meio de uma função de pesquisa e sugerir outras alternativas para tipos diferentes de resultados. Essas conexões são codificadas com metadados (informações sobre o conteúdo, como por exemplo data de criação, autor, local, uso pretendido ou idioma), a partir de esquemas diagramáticos (especificações formais e descritivas para transmitir sintaxe e estrutura) que podem ser usados por máquinas, autores e, às vezes, usuários para promover o acesso a cada tipo de informação. Dessa forma, compreende-se um alinhamento das dimensões física e digital, um amalgamento, vivenciado contemporaneamente nas diversas situações do cotidiano, sejam relações sociais, pessoais e/ou profissionais.

Retoma-se a exposição "Migrações à Mesa" em sua versão online, reconhecidamente uma outra montagem, diferente das propostas anteriores em São Paulo e Rio Grande do Sul, pois conta exclusivamente com os dados do acervo do Museu da Imigração do Estado de São Paulo. 0 website propõe uma narrativa enfatizada pela sequência linear, como dito anteriormente, que valida a horizontalidade do website, mas ainda possibilita outros movimentos pontuais de leitura pelos textos e fotografias, indicados na timeline (figura 03). Este movimento horizontal na interface enfatiza a idéia do percurso roteirizado no espaço físico já que pouco habilita derivações aos usuários, pois suas escolhas são baseadas em uma definida arquitetura de informação não rizomática. Entre as formas de pensar contemporâneas, o surgimento da "lógica da multiplicidade" e a "percepção rizomática", anunciadas em Deleuze e Guattari (1995), consti- 


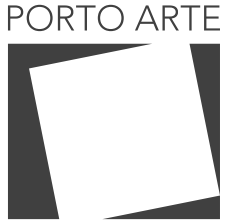

Revista de Artes Visuais

v. $25 n .43$ Jan/jun 2020 e-ISSN: 2179-8001

Figura 3: Home do website da exposição online "Migrações à Mesa". Fonte: <https:// artsandculture.google.com/ exhibit /\%C2\%AOmigra\%C3 \%A7\%C3\%B5es-\%C3\%A0mesa/5QJyihZYVv_dIW> Acesso em: jun. 2020.
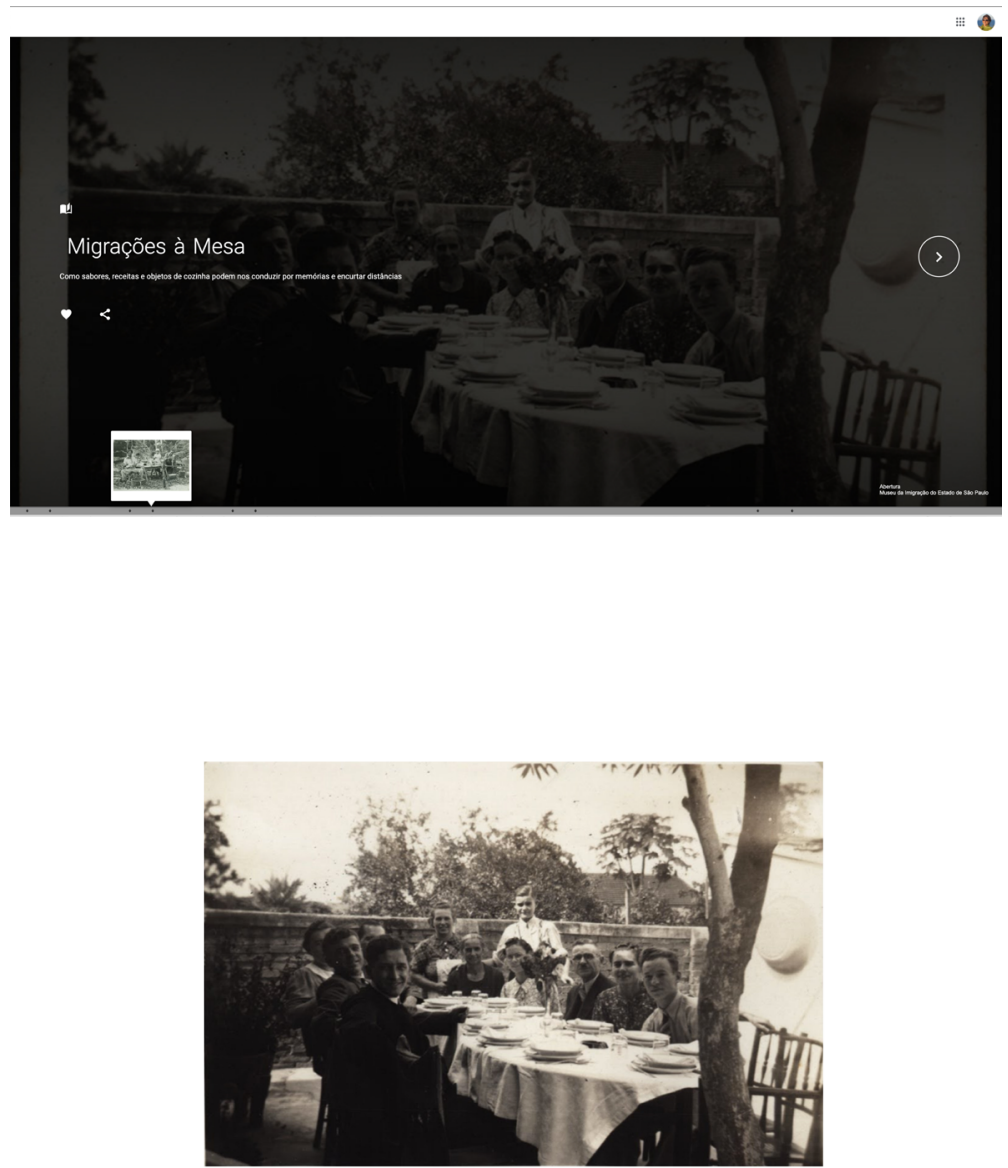

Figura 4: Interface do website

após a escolha do usuário

pela fotografia "Refeição

ao ar livre". Fonte:<http://

artsandculture.google.com/ asset/_/sAGz8Day6IEMVQ > Acesso em: jun 2020

Título: Refeiç̆o ao ar livre

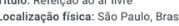

Dimensōes fisicas: $7 \times 10 \mathrm{~cm}$

Recomendado

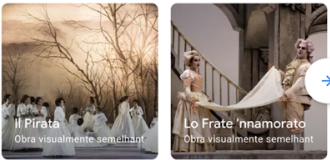


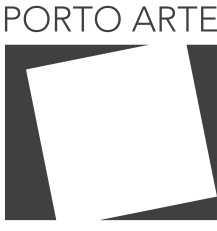

Revista de Artes Visuais

$\vee 25 n .43$

Jan/jun 2020 e-ISSN: 2179-8001

tui um marco significativo para compreender a potência das operações informacionais no ambiente digital. Ainda que a complexidade possível não tenha sido operacionalizada, percebe-se a narrativa enquanto agenciamento, ao mesmo tempo, de "fluxos semióticos, fluxos materiais e fluxos sociais", que prioriza um modelo de leitura enquanto "linha de fuga ou desterritorialização" (DELEUZE E GUATTARI, 1995, P. 32-34).

Estas imagens, com links externos à narrativa específica, compõem um banco de dados, constituindo o acervo digital da plataforma, que adiciona outros detalhes técnicos na constituição do inventário. A recomendação para o leitor (indicada em uma linha horizontal sequencial no final da interface) implica em uma associação com outras fotografias - diferentes conteúdos imagéticos, para além da narrativa expositiva, mas que também exigem uma curadoria para estabelecer as relações de semelhança: referências locais, temporais e/ou características fotográficas, todos reconhecidos como metadados na constituição da arquitetura de informação (figura 04). Ocorre uma organização conceitual mapeada em um inventário de conteúdos somente locais, ainda que potencialmente as conexões possam ser ampliadas a outros arquivos. Esta possibilidade de agenciamentos no ambiente digital atenua uma linha divisória das perspectivas documentais da narrativa expositiva, quando habilita aos usuários estados de leitura mais itinerantes e dispersos. A imagem, enquanto representação de um certo objeto, disponibiliza a contemplação e desencadeia ação: deslocamento entre diferentes conteúdos, tempos e contextos de sentido.

A possibilidade de compartilhar as fotografias em redes sociais vem referendar também a condição contemporânea de produzir, circular e atuar em rede, nas quais as interfaces digitais vem articulando o diálogo entre os participantes que experimentam, interpretam, exploram, lêem e terminam por desencadear também respostas não-reativas do sistema. Esta chamada interatividade vem sendo exaustivamente discutida e aqui não cabe discutirmos, mas importa pontuar para este texto que o ambiente computacional em rede permite situações de trocas efetivas entre humano/máquina ou entre máquina-máquina, caracterizadas por uma programação que articula invariavelmente acessos em bancos de dados para a construção conjunta da informação (quando ocorre a reversibilidade entre receptor e produtor), e não somente determina os possíveis percursos de exploração dos usuários pelas interfaces digitais.

Por mais ampla e complexa que possa se apresentar a arquitetura da informação, na narrativa online "Migrações à Mesa" todos os possíveis caminhos já estão determinados e incluídos dentro de um conjunto pré-estabelecido de escolhas, e, assim como na arquitetura física, que delimitada por contornos fixos - convenções e paradigmas previamente reconhecidos, ainda permite alguns fluxos diferentes, escapes, diante da atitude dispersiva exercitada concomitantemente pelos usuários em outras abas do browser.

É importante assim reafirmar que apesar da navegação dos usuários pelos conteúdos poder ocorrer não linearmente, existe uma estrutura da informação que organiza no campo do possível as configurações dos acessos - uma distribuição hierárquica de conexões e conteúdos a serem lidos. 0 usuário realiza seus percursos, escolhe seu ritmo, suas direções de ir e vir e estabelece suas referências e significados, sem pro- 


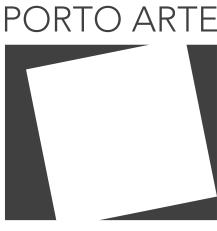

Revista de Artes Visuais

$\vee 25 n .43$

Jan/jun 2020 e-ISSN: 2179-8001

vocar no entanto nenhuma alteração nesta estrutura e/ou nos respectivos dados. As informações se dividem sucessivamente entre estados não formalizados e atualizados, fazendo de cada acesso um acontecimento singular e único. Esta estrutura possibilita a leitura da informação de maneira polissêmica, ampliando-se em várias direções de significado, simultaneamente (PARAGUAI, 1999).

Ao considerar a singularidade da leitura, também reconhecemos a individualidade dos percursos digitais. A comum tensão entre a visitação solo e a de grupo, como por exemplo a disputa pelo espaço físico ou a interação social entorno de um equipamento da exposição, esvazia-se nesta estrutura informacional, pois o usuário passa a circular sem qualquer reconhecimento da presença simultânea de outros no website. Ao contrário de ambientes multi-usuários, quando os participantes conectados podem simultaneamente alterar o mesmo banco de dados e compartilhar as mudanças, sejam as informações de caráter textual ou visual - 2D ou 3D, e até sonoro.

Esta impossibilidade de compartilhar o mesmo espaço informacional, característica da maioria dos websites, ainda que sincronizados pelos diálogos sincrônicos como os chats, parece-nos uma condição já internalizada pelos usuários e que neste momento formaliza uma atitude tão requisitada pela condição pandêmica. Podemos reconhecer este comportamento banalizado e característico de leitura ensimesmada, quando certos artistas de obras interativas assumem como tática tirar "o monitor da parede e colocar em uma mesa, para as pessoas entorno passarem a se olhar, o que pode privilegiar uma certa forma de interação social" (Jeremijenko e hoberman, 2001 apud GRAHAM e COOK, 2010, p. 133, nossa tradução ${ }^{4}$ ). Compreender o comportamento já formalizado dos usuários em websites, tanto constitui as narrativas no ambiente digital quanto tensiona as ações da mostra nos espaços físicos.

\section{Considerações finais}

A Web caracteriza-se por uma leitura dinâmica, a partir de uma estrutura hierárquica que disponibiliza as informações e pode potencialmente estimular a ação coletiva e simultânea dos usuários em diálogos instantâneos, ainda que menos reflexivos para muitos. A dimensão textual continua presente nestes sistemas e termina por configurar com os elementos imagéticos e sonoros as relações semânticas, diretamente articuladas pelo reconhecimento dos códigos culturais, pela experiência no próprio contexto tecnológico, quanto o nosso próprio olhar sobre os nossos corpos físicos.

Nesse sentido, vivências e suas representações constituem as ferramentas para que se compreenda a vida social em contexto que implica na integração entre esse desenvolvimento digital e a construção cultural e aquele que trata das questões de arquitetura na dimensão física e na dimensão informacional - o espaço, o tempo e a linguagem. Vale apontar que consideramos a exposição em sua integridade e não como constituída por elementos supostamente opostos, antagônicos, mas confluen-

\footnotetext{
4- "you take the screen off the wall and flatten it is that people around it are facing each other, which privileges a certain kind of social interaction" (JEREMIJENKO e HOBERMAN, 2001, apud GRAHAM e COOK, 2010, p. 133)
} 


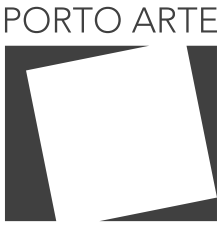

Revista de Artes Visuais v. 25 ก. 43 Jan/jun 2020 e-ISSN: 2179-8001

tes e certamente marcados pelas diferentes visões de mundo que caracterizam seus agentes organizadores. Pensar sobre as relações que os visitantes estabelecem com o ambiente expositivo nessa dupla dialogia - de sua relação com as arquiteturas e dessa relação em contexto da pandemia - ainda é um território movediço mas necessário para a garantia de uma perspectiva crítica na análise da arte e das mostras.

\section{Referências}

Albuquerque, Alfram Roberto Rodrigues de; Lima-Marques, Mamede. Sobre os fundamentos da arquitetura da Informação. Perspectivas em Gestão \& Conhecimento, João Pessoa, v. 1, Número Especial, p. 60-72, out. 2011.

BAYER, Herbert. Fundamentals of Exhibition Design. PM, v. 6, n. 2. Dec 1939-Jan 1940, p. 17-25.

BENNETT, Tony, The Birth of the Museum: History Theory, Politics. New York: Routledge, 1995.

CRARY, Jonathan. Técnicas do observador: visão e modernidade no século XIX. Rio de Janeiro: Contraponto, 2012.

CRIMP, Douglas. Sobre as ruínas do museu. São Paulo: Martins Fontes, 2005.

DEL CASTILLO, Sonia Salcedo. Cenário da Arquitetura da Arte. São Paulo: Martins, 2008.

DELEUZE, Gilles; GUATTARI, Félix. Mil platôs, capitalismo e esquizofrenia. vol. 1. Rio de Janeiro: Editora 34, 1995.

GRAHAM, Beryl; COOK, Sarah. Rethinking curating. Art after new media. Cambridge, MA; London, England: The MIT Press, 2010.

HAYLES, N. Katherine. Writing machines. Cambridge, MA; London, England: The MIT Press, 2002.

HUGHES, Philip. Exhibition Design. Londres: Laurence King Publishing, 2010.

Kahn, Paul; LENK, Krzysztof; Kaczmarek, Piotr. Applications of isometric projection for visualizing web sites. Information Design Journal, v. 10, n. 3, p. 221-228, jan.2001.

LAFUENTE, Pablo. "From the outside in Magiciens de La Terre and Two histories of Exhibitions". In: STEEDS, Lucy, et al. Making Art Global (Part 2): 'Magiciens de la Terre' 1989. London: Afterall Books (Exhibition Histories), 2012.

LOCKER, Pam. Diseño de exposiciones. Barcelona: Gustavo Gili, 2011.

O'DOHERTY, Brian. No interior do cubo branco. A ideologia do Espaço da Arte. São Paulo: Martins Fontes, 2002.

OLIVEIRA, Henry P. C. de; Vidotti, Silvana A. B. G.; BENTES, Virgínia. Arquitetura da informação. In: Arquitetura da informação pervasiva. São Paulo: Editora UNESP; Cultura Acadêmica, 2015. p. 43-74. ISBN 978-85-7983-667-1.

PALLASMAA, Juhani. Os olhos da pele: a arquitetura e os sentidos. Porto Alegre: Bookman, 2011.

PARAGUAI, Luisa. A utilização e as implicações de câmeras de vídeo na rede Internet. Dissertação de Mestrado. Departamento de Multimeios. Campinas: Instituto de Artes, Unicamp, 1999. 




Revista de Artes Visuais

v. 25 ก. 43 Jan/jun 2020 e-ISSN: 2179-8001

ROGERS, T. Museus da Europa começam a reabrir com novas regras para a era da Covid-19 em Folha de São Paulo, 14 de maio de 2020. Publicado inicialmente em New York Times. Disponível em <https://www1.folha.uol.com.br/ ilustrada/2020/05/museus-da-europa-comecam-a-reabrir-com-novas-regras-para-a-era-da-covid-19.shtml>. Acesso em: jun. 2020.

SISEMSP. Receitas tradicionais de famílias migrantes é o tema de 'Migrações à mesa' 2016. Disponível em <https://www.sisemsp.org.br/receitas-tradicionais-de-familias-migrantes-e-o-tema-de-migracoes-a-mesa/>. Acesso em: jun. 2020.

STDM. Migrações à mesa. 2016. Disponível em <http://www.stdm.com.br/index\#/migraes-mesa/>. Acesso em: jun. 2020.

VIÑAO FRAGO, Antonio; ESCOLANO, Augustín. Currículo, espaço e subjetividade: a arquitetura como programa. 2a ed. Rio de Janeiro: DP\&A, 2001.

WURMAN, Richard Saul. Information Architects. New York: Graphis Inc., 1997. 


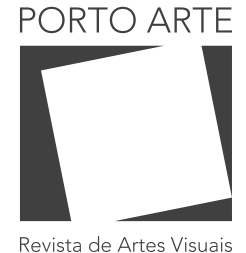

v. $25 n .43$ Jan/jun 2020 e-ISSN: 2179-8001

Texto recebido em: $21 / 06 / 2020$ Texto publicado em: $30 / 06 / 2020$

\section{Mirtes Marins de Oliveira}

Mestre e doutora em Educação: História e Filosofia. Docente e pesquisadora na Pós-Graduação em Design da Universidade Anhembi Morumbi e Pós-Doutora pela FE-USP. Coeditou, com Lisette Lagnado, a publicação Marcelina (2008-2012). Curadora de: "contra o estado das coisas - anos 70"(2014); "Arte para todos! Liberação e Consumo"(2018) e "especular"(2018). Participou, em 2015, do livro "Cultural Anthropophagy: The 24th Bienal de São Paulo 1998", da coleção Exhibition Histories, da editora inglesa Afterall. Escreveu em 2013 e 2014 para revistas Select e Afterall Online. Organizou, com Fabio Cypriano, o livro "Histórias das Exposições: Casos Exemplares", pela EDUC (2016). Autora de "The body and the opus as a witness of times". The SAMMLUNG VERBUND Collection. Vienna, 2017. Escreveu para revistas e plataformas Select, Arte Brasileiros!, Artsoul. Realizou, em 2019, a exposição "Comigo ninguém pode", coletiva versando sobre a essencialização do feminino.

\section{Luisa Angélica Paraguai}

Pesquisadora e Docente permanente do Programa de Pós-Graduação em Linguagens, Midia e Arte da Pontifícia Universidade Católica de Campinas. Bolsista de Produtividade em Pesquisa do CNPq - Nível 2. Consultora Ad Hoc da CAPES e FAPESP. Reviewer da Leonardo Digital. Vice-líder do Grupo de Pesquisa Produção e Pesquisa em Arte. Pesquisadora e artista nas interlocuções entre arte, design e tecnologia, investiga linguagens e materialidades, que operacionalizam experiências perceptivas. Possui graduação em Engenharia Civil na Universidade de São Paulo (USP), mestrado e doutorado em Multimeios, Instituto de Artes na Universidade Estadual de Campinas (UNICAMP), e pós-doutorado no Planetary Collegium, Nuova Accademia di Belle Arti NABA, Milão. Atualmente desenvolve estágio pós-doutoral no MediaLab/UFG 